\title{
Preconditions and Preparatory Steps of Implementing CLIL for Future Mathematics Teachers
}

\author{
Nina Tarasenkova ${ }^{1, *}$, Iryna Akulenko ${ }^{2}$, Iryna Kulish ${ }^{3}$, Iryna Nekoz ${ }^{3}$ \\ ${ }^{1}$ Department of Mathematics and Methods of Teaching Mathematics, Educational-Scientific Institute of Informational and \\ Educational Technologies, Bohdan Khmelnytsky National University of Cherkasy, Ukraine \\ ${ }^{2}$ Department of Algebra and Calculus, Educational-Scientific Institute of Informational and Educational Technologies, Bohdan \\ Khmelnytsky National University of Cherkasy, Ukraine \\ ${ }^{3}$ Department of Foreign Languages, Educational-Scientific Institute of Foreign Languages, Bohdan Khmelnytsky National \\ University of Cherkasy, Ukraine
}

Received December 29, 2019; Revised January 30, 2020; Accepted February 19, 2020

Copyright $\odot 2020$ by authors, all rights reserved. Authors agree that this article remains permanently open access under the terms of the Creative Commons Attribution License 4.0 International License

\begin{abstract}
This article focuses on the problem of implementing the integrated learning of Mathematics and English by future Mathematics teachers based on the Content and Language Integrated Learning (CLIL) model. Our review of the literature confirms that this method is considered to be an effective approach to the formation and development of students' subject knowledge and foreign language skills. This technology is significant for the professional training of future Mathematics teachers since they should be competent in both Mathematics and foreign language to effectively teach today's schoolchildren. A student questionnaire was conducted and its analysis shows that students believe that CLIL will benefit them in the process of their professional training. Since the CLIL approach is multidimensional process, its implementation requires thorough preparation. This paper demonstrates and describes some specific steps in the preparatory stage for implementing the CLIL approach for the professional training of future Mathematics teachers: determining mathematical course, choosing its specific themes (units), planning for expected results, designing the organizational features of the educational process using the CLIL method and designing the appropriate teaching and methodological support. The possible variant for designing the preparatory stage for the integrated teaching and learning of "Number Theory" and English is suggested. It is demonstrated that the Mathematical and foreign language component of the expected educational outcomes need to be distinguished. The educational process should involve a special system of multilevel bilingual assignments. It also should have some special preconditions and joint activities of Mathematics and English teachers.
\end{abstract}

Keywords Content and Language Integrated Learning (CLIL), English for Specific Purposes (ESP),
Implementation Process, Preparatory Stage, Foreign Language Competence, English Language Competence, Multilevel Bilingual Assignments

\section{Introduction}

The Mathematics teacher in the modern society lives and works in a globalized world, communicating with students and colleagues including both his/her compatriots and citizens of other countries. Therefore, a significant result of students' professional training is the formed ability to present, discuss and argue personal views on various aspects of teaching Mathematics in oral and written forms, using, in particular, foreign languages. In addition, the professional development of a young specialist in the modern society is impossible without of the process of learning the latest developments in both the fields of Mathematics and Didactics of Mathematics that are published in foreign editions. For this purpose, the future teacher needs to have a sufficient level of foreign language communication (linguistic) competence and to gain an experience of professional foreign language communication.

It is difficult to provide such a result because mastering mathematical content and forming communication skills in a foreign language are different processes in their content and patterns. However, studies $[1 ; 2 ; 3 ; 4 ; 5 ; 6]$ show that it is possible to solve this problem through the integrated learning of a foreign language and the disciplines in the cycles of general and vocational training of a future teacher at the university.

The integrated learning of content and a foreign language, as shown in studies [5[5]], can be implemented 
in different models of the educational process. The first model, e.g., is learning English for Specific Purposes (ESP), the second one is Content and Language Integrated Learning (CLIL). The ultimate goal of these two approaches coincides because not only subject mathematical competence but also foreign-language communicative (linguistic) competence of future specialists should be formed in both cases. However, significant features differentiate these approaches in terms of intermediate learning goals, content, process and learning outcomes.

The ESP approach concentrates on providing future professionals with the professionally needed foreign language skills, while CLIL gives the opportunity to obtain simultaneously both professional and foreign languages knowledge and skills. ESP is taught by English Philology teachers, while CLIL is taught by Mathematics teachers speaking English at the level of B2-C2. In the first case, the educational process focuses on developing foreign language communicative (linguistic) competence, particularly, students' ability to use foreign language knowledge and communicative skills in the professional environment. Mathematics knowledge and skills form a background, a tool for developing communicative foreign language skills. Therefore, the development or improvement of subject mathematical competence is a secondary and incidental result achieved partially, occasionally, unsystematically. In the second case, the main result of the educational process is subject mathematical knowledge and the ability of students to implement the methods of mathematical activity. At the same time, foreign language communication competence is developed in the background way, and is the accompanying learning outcome.

The main difference of the CLIL approach (Marsh) [1] is that it aims at simultaneous equal development of two components of a future specialist's professionalism, namely, subject mathematical and foreign language communicative competences. In the educational practice, it is distinguished by a dual purpose, implemented by two teachers who design and provide training, characterized by the fact that the educational subject (mathematical) material is presented in a foreign language. The implementation of the CLIL approach requires providing certain preconditions and thorough preparation. In this paper, we consider one of the possible variants of preparatory stage of the CLIL implementation.

\subsection{The Goals of the Article}

1) to substantiate and describe the certain steps in the preparatory stage for implementing the CLIL approach in the professional training of future Mathematics teachers;

2) to suggest the possible variant of designing the preparatory stage for implementing the CLIL approach for the integrated teaching and learning Mathematics and English.

\subsection{Literature Review}

At the present stage of pedagogical science development, CLIL is considered to be an innovative approach in pedagogy being effective in the formation and development of subject knowledge and foreign language competence of students. However, researches (Wielander [2]) confirm that this approach has ancient historical background. According to Hanesová [3], CLIL is based on the elements and certain achievements of various learning pedagogical approaches formed for historical or territorial reasons in a number of countries where learning process of different educational levels occurs with the involvement of a foreign language.

The modern term of CLIL was coined by Marsh in 1994 [4] who defined this method as an approach involving situations where subjects or parts of subjects are taught in a foreign language and focus on dual purpose, namely, simultaneous learning of content and a foreign language. Cambridge dictionary defines [5] the concept of CLIL as an abbreviation for content and language integrated learning (in some countries), a teaching method that involves teaching students about a subject in a foreign language. For the last several decades, CLIL has been considered [6] to be an effective way of achieving a high level of language proficiency, improving subject and language competence, and enhancing learning motivation.

Our analysis of the literature sources shows that most researchers (Dudley-Evans, St John [7], Inozemtseva, Bondaletova, Borisova [8; 9], Coyle, Hood, \& Marsh [13]) confirm differences in the ESP and CLIL technologies. The first technology focuses on the subject completion of a foreign language course according to the specialty of students, while the second one is essentially a bilingual, interdisciplinary training that focuses on both the content of a particular discipline and the study of a foreign language.

The basic concept of CLIL (Coyle [14]) is 4Cs conceptual framework: content of the learnt subject, communication in oral and written form on the subject, cognition as a development of cognitive abilities of students while learning a subject and a foreign language, and culture involving a wide range of cultural context aimed at the development of students' responsibility for global and local environment. The approach is based on the concept of integration implemented in different models.

Paper [7] describes such three models of CLIL: soft CLIL, the so-called language-led approach with attention being focused on linguistic features of the special context, and hard CLIL, the so-called subject-led approach with $50 \%$ of the subject curriculum being studied in a foreign language. The third model occupies an intermediate position and is used when some module subject curricula are learnt in a foreign language (partial immersion).

The researchers (Coyle, Hood, \& Marsh [13]) 
distinguish the following CLIL principles.

1. Authenticity. The CLIL approach uses authentic materials and learning situations, for example, to reproduce real life situations.

2. Multitasking. Teaching process focuses on several areas: understanding the subject matter; developing cognitive skills through the content analysis; developing presentation and discussion skills; developing foreign language skills; forming cooperation among students in the group work mode (correspondence to time frames, work with sources of information); developing ICT skills.

3. Active training. Students are actively involved in learning process at both the project preparation stage and presentation stage. They are responsible for involving other students in the project. They also develop peer assessment criteria and evaluate each other themselves.

4. Safe learning environment. It is ensured by creating a friendly environment and equal opportunities for all students, which, to a certain extent, overlaps with important psychological and pedagogical principles on creating a comfortable environment for students while learning a foreign language.

5. Scaffolded instruction. Based on the concept of the "zone of proximal development" by L. Vygotsky, the idea of J. Bruner about the need to create learning supports being gradually eliminated as students gain autonomy of learning actions, is implemented within CLIL as the basis of the teacher's methodical actions.

The researches of Mehisto, Marsh, \& Frigols Martin [16] confirm these principles.

Dalton-Puffer [17] distinguishes the following stages of the educational process in CLIL, namely: description (identification, definition, classification, etc.), explanation (examples, development, abbreviation, etc.), evaluation (proof, argumentation, etc.), conclusions (final outcomes, explanations of results, etc.). Italian researchers Favilli, Maffei, Peroni [29] stress that CLIL is based on three different language types: the dialogic, the descriptive, and the argumentative ones. The dialogic (content non-specific) language is characterized by the use of colloquial linguistic expressions and very limited use of content specific expressions. It is used by the teacher to introduce a specific mathematical content that the teacher considers familiar to the students. The descriptive (content semi-specific) language is characterized by a rich amount of the descriptions of common descriptive discourse. Such type of discourse is used by the teacher in order to pose a problem. The argumentative (content-specific) language is a type of argumentative language which is characterized by the formal language used mainly in an argumentative style, also by the support of specific mathematical symbols and formulas. Researchers point out that all the language types surely impact the effectiveness of CLIL in mathematics classroom.
The CLIL implementation needs appropriate educational and methodological support. Bystray, Belova, Vlasenko, Zasedateleva, \& Shtykova [11] study the means of the CLIL approach, particularly, the features of special texts and system of exercises that become the basis for reaching the CLIL educational goals. They state that the text as a source of information presents a specific topic to a reader, but it also serves as a basis of the lexical and grammar module that provides acquisition of the scientific technology and certain grammar and structural-stylistic constructs. The text in CLIL should serve as a starting point for the discussions and the expansion of the vocabulary on the given topic, thus simultaneously stimulating the development and activation of communicative skills of dialogue and monologue speech.

Safarova [31] stresses that in terms of the CLIL approach, learning material should be selected at the complexity level slightly lower than the actual level of students' knowledge in this subject in their native language. Texts should be thoroughly selected and supplied with a sufficient number of tasks for understanding and mastering the material. Tasks on the texts should be built with an emphasis on the subject matter, involve students in the process of understanding, checking, discussing the main idea of the text. The tasks should show the features of linguistic forms, practice the ability to create and use them, apply different types of testing and evaluation (including mutual control). The tasks should stimulate independent and creative activity of students, involving communicative tasks for oral and written communication in a foreign language. Students should first be introduced to the compensatory strategies to solve language, content, and communication problems.

Researches $[5 ; 6 ; 9 ; 10$ and others] stress that CLIL in the combination with ESP are applied at different educational levels (in preschool, primary, secondary and higher education).

Belgian educators Surmont, Struys, Van Den Noort, \& Van De Craen [21] study the efficiency of teaching Mathematics based on the CLIL technology at secondary school. Their statistical data indicates that CLIL positively affects not only the language learning but also content acquisition, has a positive impact on the mathematical performance of students even after a short period of time. Their studies prove that CLIL possibly influences pupils' cognitive development, and more specifically, their metalinguistic awareness. The increased metalinguistic awareness can lead to a better understanding of Mathematics and insight into the abstract language of it. To improve Mathematics performance, bridges between learning a language and Mathematics (and science for that matter) should be created. Their results indicate that the combination of a language and content has a positive effect on cognitive development.

The participants of Polish project with the support of the European Union "Two Highways of Life - Mathematics and English" make generalization, conclusions and 
recommendations [22] as to the improvement of Mathematics education on the basis of CLIL. They stress the importance of CLIL as the approach that helps students to develop the skills of both the native and foreign language. This approach gives students different educational experience compared to the traditional study of English since applying the CLIL approach, subject material and a foreign language are learnt together. In addition, the general educational skills and logic thinking are developed. The CLIL technology can involve alternative teaching methods (of both Mathematics and a foreign language). This approach presents new objectives and challenges for teachers and students.

Researches $[12 ; 13 ; 15 ; 17 ; 18 ; 19 ; 20$ et al.] consider this technology has significant importance and wide application in adult education, in occupational and professional training. Estonian scientist (Käbin [18]) studies the efficiency of the ESP courses in occupational training of medicine and service professionals. The importance of CLIL in the engineer education in the combination with technology perspectives focused on the innovations and entrepreneurship is studied by Spanish educators (Lorenzo, Trujillo, \& Vez [19]). Ukrainian scientists Vlasenko, Lovyanova, Chumak, Sitak, \& Kalashnykova [20] study the formation of the foreign language competence of engineering students by means of CLIL. The researchers apply the CLIL method on the example of Elementary Mathematics course integrated with the English language learning. They confirm that the integrated elective course of English and Elementary Mathematics has a positive impact on forming the foreign language competence of engineering students, as well as on the improvement of their motivation to study.

Jordan researchers Miqdadi, \& Al-Jamal [30] study the difficulties (epistemological, pedagogical, personal and discourse) encountered by the integrated teaching and learning Mathematics and English. Discourse problems rise because students come to the university with different sometimes insufficient knowledge of many mathematical concepts in Arabic. Pedagogical problems are relevant to teaching process in terms of presentation methods, teacher's preparation, assessment, the ways of material presentation and mostly knowledge proficiency. Researchers identify epistemological problems as the problems that may be attributed to the difficulty of the nature of mathematics and the abstractness of mathematical concepts. The authors recommend that it is necessary to reinforce the foundation of English and later to lay the basis of CLIL with the help of English for Specific Purposes.

Thus, the analysis of literary sources makes it possible to draw the following conclusions. Although CLIL is considered to be an innovative method of modern pedagogy, the foundations for the creation of this technology emerged long ago. CLIL is considered to be an effective way to achieve a high level of the language proficiency, to improve subject and language competence, and to increase learning motivation.

The review of literature shows that although CLIL is widely used in the learning process of different educational levels (basic, occupational, higher), but the problem of improving professional training of a future Mathematics teacher based on the implementation of CLIL requires scientific consideration, research and comprehension. This is primarily due to the fact that one of the significant results of secondary education is the formation of students' foreign language competence. This means that a teacher should also develop such competence at the level not lower than students' one. In addition, applying of the CLIL technology in the process of the professional training of a future Mathematics teacher also creates favourable conditions for the formation of a young professional's ability to organize further teaching of school students on the basis of the CLIL technology. This will have a positive impact both on the level of school students' mathematical achievement and communicative foreign language competence.

However, despite the wide range of studies devoted to the implementation of the CLIL method, in our view, there are insufficient researches concerning the efficient technologies of the preparatory stage of the CLIL implementation.

\section{Materials and Methods}

To determine the regularities of the preparatory stage for the CLIL implementation according to our approach, we consider its features. First of all, we suggest implementing the integrated foreign language and mathematical training of a future Mathematics teacher in two stages, consistently implementing the ESP and CLIL models.

Learning a foreign language by the first- and second-year students of mathematical specialties should have professional orientation. Therefore, the application of the ESP model is more appropriate during the first and the second years of students' professional training. It is primarily focused on enriching students' vocabulary with the special professional terminology, on expanding their grammatical and lexical minimums. The ESP model is implemented individually by a teacher of a foreign language. The educational process on the ESP model provides conditions for students to apply common foreign language knowledge and skills, in particular during oral and written contacts in the situations of professional communication.

Based on the ESP learning, we conducted a student questionnaire of learning outcomes in mastering basic language and speaking skills of the professional-oriented English to analyze their self-esteem and to study their needs.

The students were asked to select positions that were appropriate for their language and speaking skills after ESP learning. The results of students' subjective evaluation of their skills are presented in Table 1. 
Table 1. Results of Student Questionnaire

\begin{tabular}{|l|c|}
\hline \multicolumn{1}{|c|}{ Language and speaking skills } & Percentage of selected options \\
\hline I understand mathematical terms and terminological expressions while reading English texts & 87 \\
\hline I understand mathematical terms and terminological expressions while listening tasks or problems & 66 \\
\hline I recognize new mathematical terms and terminological expressions by familiar roots or affixes & 58 \\
\hline I use mathematical terms and terminological expressions in speaking & 39 \\
\hline I use mathematical terms and terminological expressions in writing & 47 \\
\hline I formulate my thoughts using appropriate grammar structures while speaking & 32 \\
\hline I formulate my thoughts using appropriate grammar structures while writing & 42 \\
\hline I understand professional-oriented speech in English & 82 \\
\hline I did not acquire any learning skills while learning ESP & 0 \\
\hline
\end{tabular}

The results of the student self-esteem show that the majority of students thinks that they have lexical skills and skills of reading concerning mathematical terminology $(87 \%)$ and more than half of students can extent their potential vocabulary at the expense of known roots and affixes (58\%). The significant part of the students has listening skills concerning professional situations of communication $(66 \%)$. Almost half of students have writing skills (47\%) and one third of them have the formed grammar skills in oral speech $(32 \%)$. The percentage concerning grammar skills in writing is higher (42\%). In general, the majority of students thinks that they have language skills concerning professional situation. However, low percentage in some positions show that students have certain problems mostly concerning their low level of basic foreign language skills formed at school and motivation.

In addition, we conducted student questionnaire to study their motivation for improving mathematical and foreign language skills by content and language integrated learning.

The questionnaire results show that over half of participants think that the ESP skills do not help them to learn mathematical subjects $(57 \%)$ and almost half of them believe that skills in the professional-oriented foreign language promote to master mathematical disciplines $(43 \%)$. Evaluating the number of practical lessons in a foreign language, the majority of students considers them to be sufficient to develop the skills of reading mathematical texts independently (71\%) and almost half of students - to understand mathematical texts (43\%) and to reproduce definitions of mathematical concepts in a foreign language $(41 \%)$. Only $29 \%$ of students think that the number of the ESP practical lessons are sufficient to reproduce mathematical statements in English. Two positions with $0 \%$ show the lack of the ESP practical lessons to understand a theorem proof in English and to reproduce a theorem proof in English.

Analyzing their foreign language skills, most participants believe that after learning ESP, they are able to formulate the English definition of certain mathematical concepts orally $(73 \%)$ and understand the basic context of mathematical texts while reading $(71 \%)$. However, only
$30 \%$ of students think they are able to formulate the English definition of specific mathematical concepts in writing, $29 \%$ - to formulate any learnt theorem orally, $28 \%$ - to understand the basic context of mathematical texts while listening and $25 \%$ - to understand a theorem proof in English. The students do not think they are able to write a hypothesis and conclusion of any theorem in English and translate a theorem proof from Ukrainian into English.

The questionnaire shows that most students would like to learn mathematical subjects using content and language integrated learning (learning Mathematics in English) $(85 \%)$. The students would prefer to learn only some themes of a separate module of a mathematical discipline in English (57\%), some modules of a certain mathematical discipline in English (28\%) and half of mathematical subjects in English (15\%). Furthermore, most students would like to continue their learning ESP along with learning Mathematics in English (71\%).

Consequently, the students' questionnaire results confirm that ESP course for Mathematics students promotes the lexical skill formation and development of the professional-oriented vocabulary, however, the number of practical lessons is insufficient to understand a theorem proof in English and to reproduce a theorem proof in English. The fact that most students would like to learn mathematical subjects using content and language integrated learning (learning Mathematics in English) confirms the students' awareness of the importance of improving both mathematical and foreign language competence for their future career as Mathematics teachers.

According to the questionnaire results, we make a conclusion that CLIL should be implemented in the process of the professional training of students. We propose to apply the CLIL model during the third and the fourth years of study at the university. However, before introducing the educational process on this technology, its preparatory stage must be carefully thought out and implemented. The results of the student survey and analysis of the literature on the subject of the integrated study of Mathematics and English make it possible to develop a model of the preparatory stage for the introduction of CLIL. 


\section{Results and Discussions}

Since CLIL should be implemented in the joint activity of a student, a Mathematics teacher and an English teacher, the model of preparatory stage for CLIL implementation reflects their trilateral interaction. In the joined activity of a student and an English teacher, the student's basic level of knowledge and skills in General English (GE) and ESP is formed. Students and Mathematics teachers jointly determine a model of the integrated learning of Mathematics and English (soft-CLIL, hard CLIL, intermediate CLIL), choose a Mathematics course or a content module of a specific mathematical discipline for the integrated learning, formulate the integrated expected results. Mathematics and English teachers jointly distinguish mathematical and linguistic components of the expected results, jointly plan the organization of educational process, and form educational support (collection of educational mathematical texts in English, a system of bilingual tasks) (Fig. 1).

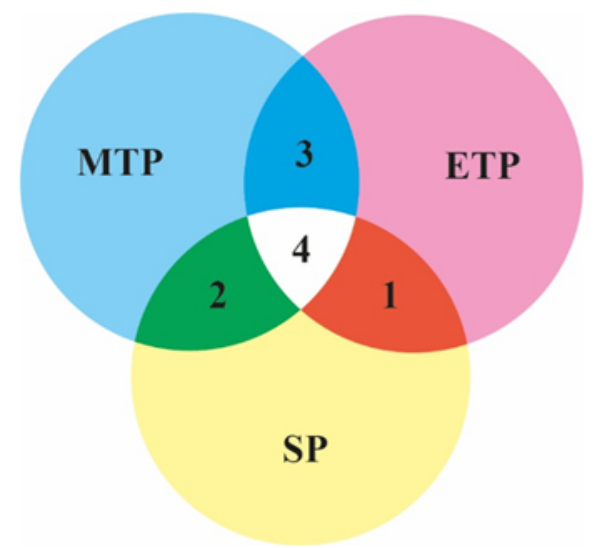

MTP - Mathematics Teacher Preparation

ETP - English Teacher Preparation

SP - Student Preparation

1 - English teacher and students jointly improve students' English skills while learning General English (GE) and English for Specific Purposes (ESP)

2 - Mathematics teacher and Students jointly choose a model of the integrated learning of Mathematics and English, choose a Mathematics course or/and a certain content module, formulate the integrated expected results

3 - Mathematics and English teachers jointly distinguish mathematical and linguistic components of the expected results, plan the organization of educational process, and form educational support

4 - General Result of Preparatory Stage (general concept of CLIL implementation adapted to certain conditions, Students' motivation for integrated learning Mathematics and English)

Figure 1. Model of Preparatory Stage

We suggest implementing this model through the following steps: 1) to provide the formation of student's basic level of knowledge and skills in GE and ESP; 2) to determine mathematical course and/or specific themes (units) of the course as a basis for implementing the integrated learning of Mathematics and English; 3) to plan the integrated expected results and specify their mathematical and English component; 4) to determine the organizational features of the educational process using the CLIL method; 5) to substantiate the general concept of the CLIL implementation and its adaptation to certain conditions; 6) to design the appropriate teaching and methodological support of the integrated learning of Mathematics and English based on the accepted concept.

\subsection{Design of the Integrated Learning of Mathematics and English Using the CLIL Method}

We suggest implementing CLIL technology in teaching some themes of the course previously learnt by students since, in this case, mathematical component is familiar to students and they focus their attention on foreign language component. Particularly, students will have a chance to practice the reproduction and translation of mathematical statements and concepts in English. At the same time, this will create the preconditions for certain extension or deepening of previously learnt mathematical content. In addition, students will have additional opportunities to practice the under-formed mathematical activities by filling in the gaps in theoretical knowledge.

We suggest choosing "Number Theory" course for the educational process using the CLIL technology. The "Number Theory" course is chosen for several reasons. First, the content of the course is crucial for the formation of both subject mathematical and methodological competence of a future Mathematics teacher, since it is introduced in a short and adapted form into the algebra curriculum (K-8, advanced level of Mathematics learning). Second, the applied aspects of this material, namely its application in cryptology, can be considered in the elective interdisciplinary (Mathematics and Informatics) course of "Fundamentals of Cryptology". Appropriate methodological recommendations for teachers to introduce this elective course into the educational process are presented in $[23 ; 24 ; 25]$. Finally, the content of this course provides an opportunity for students, future Mathematics teachers, to form and develop speech competence, in particular, during the formulation of basic concepts and their properties.

Since students propose to choose some themes of certain course for the CLIL method, our suggestion involves the following themes of the course.

Theme 1. The ratio of divisibility in the ring of integers. The remainder theorem. The greatest common divisor (GCD) and the least common multiple (LCM) of numbers. Euclid's algorithm. Coprime integers.

Theme 2. Primes (theorems and problems). The fundamental theorem of arithmetic (FTA), the unique factorization theorem. Numerical functions $\tau(n) ; \varphi(n) ; \sigma(n)$.

Theme 3. Infinite simple continued fractions and the convergents of the continued fraction.

Theme 4. Definition of congruence by the given module, properties (by the fixed module, by different modules). Reduced residue system, Euler's and Fermat's theorems. 
Theme 5. One-variable congruences, linear congruences.

Theme 6. Second degree congruent. Quadratic residues, nonresidues. The Legendre symbol. Euler's criterion for quadratic residues and nonresidues.

It is these themes that give an opportunity to master the art of argumentation in proving mathematical facts (theorems). Some of these theorems (the remainder theorem, Fermat's little theorem (a consequence of the Euler's theorem), the prime number theorem, the divisibility theorems) are also learnt in Algebra course in K-8. However, the rigour level of proofs presented in this course and in the school Mathematics is different. Future teachers have an opportunity to master and reproduce the ways of thinking in a foreign language at different levels of rigour and to compare them. Thus, future teachers improve their mathematical and language competence (its logic, lexical, grammar components) while studying the course of "Number Theory".

We suggest implementing the CLIL technology at elective classes or introducing an appropriate course of students' choice, thus creating an individual educational path of professional training of a future Mathematics teacher.

Mathematics and English teachers should develop the joint syllabus in terms of teaching these themes. While developing the syllabus, we suggest distinguishing mathematical and foreign language component of the expected results of students' learning activity (Table 2).

Table 2. Mathematical and Foreign Language Components of Expected Results

\begin{tabular}{|c|c|}
\hline Mathematical component of expected results & $\begin{array}{c}\text { Foreign language component of expected } \\
\text { results }\end{array}$ \\
\hline 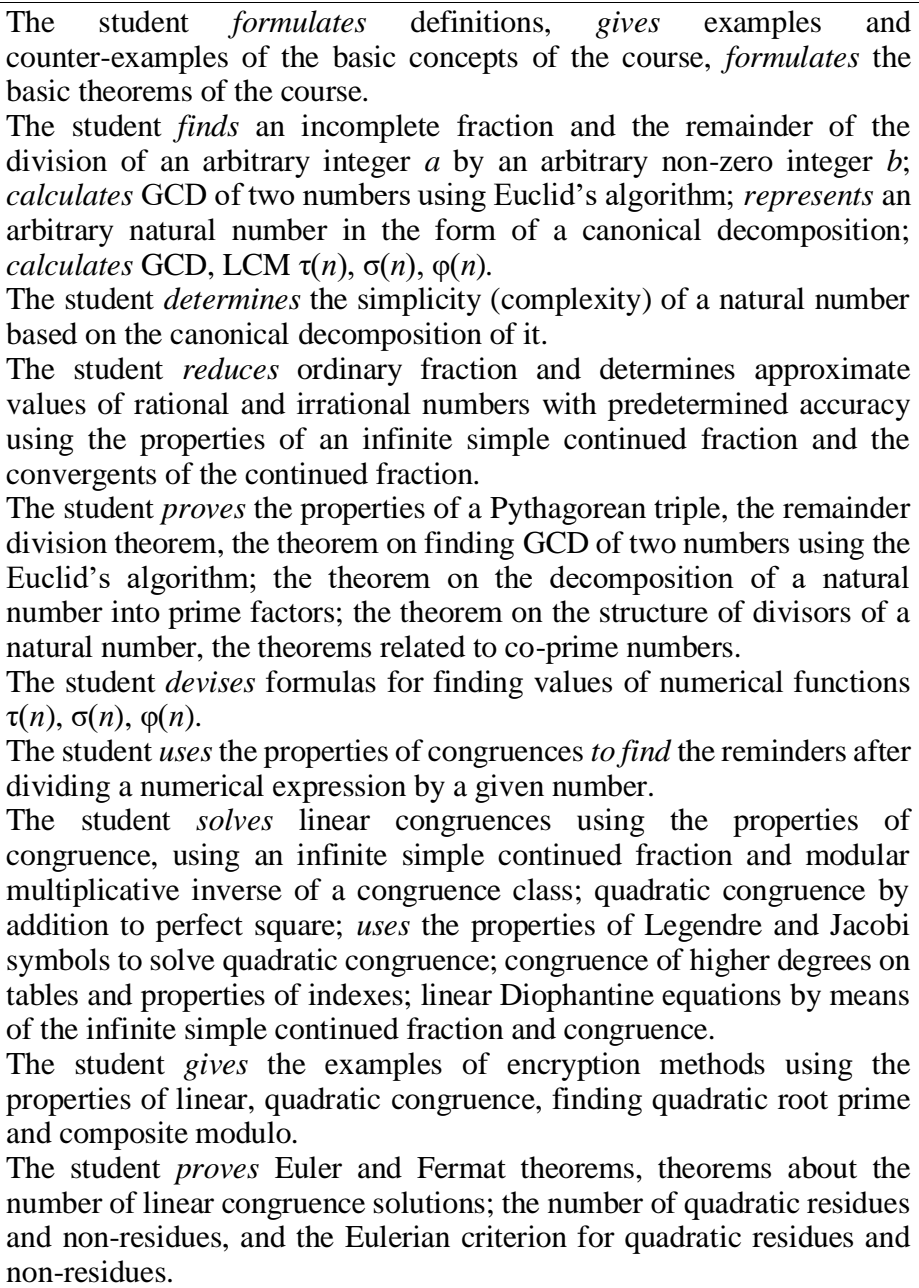 & $\begin{array}{l}\text { The student understands the meaning of the } \\
\text { words in a lexical minimum of the foreign } \\
\text { language (FL); forms new words using affixes } \\
\text { of FL; forms sentences of different structural } \\
\text { types of FL; paraphrases utterances for a given } \\
\text { purpose; distinguishes between synonyms of } \\
\text { the learnt concepts; distinguishes between true } \\
\text { and false statements; forms necessary } \\
\text { grammatical forms of the words in FL; writes } \\
\text { words and sentences using spelling and syntax } \\
\text { rules of FL; analyzes the word formation in FL; } \\
\text { analyzes sentence structure of FL; uses } \\
\text { necessary units of lexical and grammatical } \\
\text { minimum of FL. } \\
\text { The student comprehends materials that are } \\
\text { read and heard in FL; evaluates and analyzes } \\
\text { what is read and heard in FL; reproduces what } \\
\text { is read and heard in FL; plans and formulates } \\
\text { future utterances in FL; implements the idea of } \\
\text { speaking in the process of speech activity in FL; } \\
\text { corrects own speech and the speech of others; } \\
\text { pronounces certain results in FL; reproduces } \\
\text { information content in FL; uses professional } \\
\text { and interdisciplinary knowledge in speech } \\
\text { activity in FL. } \\
\text { The student joins the problem discussion in FL; } \\
\text { supports discussion on a given topic; uses } \\
\text { language means in the communication } \\
\text { appropriately; gives arguments to them; is } \\
\text { oriented in the situation of communication in } \\
\text { FL; establishes contact with an interlocutor; } \\
\text { changes strategy and speech behaviour } \\
\text { depending on the communicative situation; has } \\
\text { discussion in FL; supports or denies the views } \\
\text { of an interlocutor. }\end{array}$ \\
\hline
\end{tabular}


The CLIL technology should be based on students' experience gained at mathematical disciplines and learning ESP during the first and the second year of their study at the University. The character of teaching process using the CLIL approach should be student-centered and interactive. The introduction of a new material of mathematical content by the Mathematics teacher should be previously regulated and agreed with the English teacher.

Education should provide the implementation of four types of activities at classes: reading, listening, speaking and writing in English. These activities should be combined with the methods of mathematical activity appropriate to the mathematical component and comprehensive feedback.

The foreign language component will be realized in the process of mastering mathematical content by students. Teaching and learning processes should facilitate the students' mastering mathematical content and performing additional assignments with foreign language load. So, the educational process needs to involve a special system of multilevel bilingual assignments.

\subsection{A System of Bilingual Tasks to Achieve the Expected Results}

Since CLIL is a task-based language learning approach by which the language is learned through its use while discussing content matter and solving assignments, we consider the features of a system of bilingual tasks to be aimed at achieving the expected results when studying the course of "Number Theory". To systematize the bilingual tasks, the ideas of Tarasenkova and Borkach [28] were used. The system of the bilingual tasks is structured in several groups.

The first group includes the tasks for mastering terminology. The second group consists of the tasks which are aimed toward reproducing the bilingual wording of mathematical statements. The third group represents the tasks which teach students to create the bilingual related texts (comments on the implementation of methods of mathematical activity).

The first group includes three-level terminological tasks. The first level tasks are related to the formation of students' ability to establish bilingual terminological pairs of concepts within a specific content module or topic study. The tasks of the second level require to create bilingual comparative conceptual terminological tables, terminological clusters that reflect the links between the concepts studied. We associate the tasks of the third level in this group with students' training to formulate bilingual definition of a concept independently. Here are some examples.

Task 1.1 (first level). Give the Ukrainian equivalents to the following concepts: congruence, integers that are congruent modulo $m$, prime (composite) integers, the greatest common divisor (GCD), the lowest common multiple (LCM), co-prime integers, canonical decomposition of a natural number, a complete (reduced) residue systems modulo $m$, a linear congruence, a solution of the linear congruence, equivalent linear congruencies, elementary transformations of congruencies, modulo multiplicative inverse of the congruence class, modular multiplicative inverse of an integer $a$, linear representation of GCD of two natural numbers, a system of congruencies, a solution of a system of congruencies, Euler's totient function, a multiplicative function, a quadratic congruence, a quadratic residue modulo $m$ and a quadratic nonresidue modulo $m$, a square root modulo $m$.

Task 1.2 (first level). Give the English equivalents to the following concepts: подільність націло в кільці цілих чисел; найбільший спільний дільник (НСД) та найменше спільне кратне (НСК) двох або кількох чисел; лінійне представлення НСД двох чисел; взаємно прості числа; просте число; канонічний розклад числа; мультиплікативна функція.

Task 1.3 (first level). Find the correspondent definition to the concepts (table 3 ).

Table 3. The Concepts and Definition

\begin{tabular}{|l|l|}
\hline \multicolumn{1}{|c|}{ Notion } & \multicolumn{1}{c|}{ Definition } \\
\hline Congruence modulo & $\begin{array}{l}\text { For every finite set } a_{1}, a_{2}, \ldots, a_{k} \text { of positive integers, there exists a largest integer that divides each of these } \\
\text { numbers, called their___ }\end{array}$ \\
\hline Congruent modulo $m$ & is any positive integer greater than 1 that is divisible only by itself and 1 \\
\hline $\begin{array}{l}\text { Greatest common divisor } \\
\text { (GCD) }\end{array}$ & Two integers $a$ and $b$ are said to be___ if their difference $a-b$ is divisible by the integer $m$. \\
\hline $\begin{array}{l}\text { Lowest common multiple } \\
\text { (LCM) }\end{array}$ & $\begin{array}{l}\text { If } a \text { is congruent to } b \text { modulo } m, \text { this statement is written in the symbolic form } a \equiv b \text { (mod } m \text { ). Such } \\
\text { symbolic record is called___ }\end{array}$ \\
\hline $\begin{array}{l}\text { Prime number } \\
\text { A smallest positive integer that is a multiple of each of the given integers is called their___ }\end{array}$ \\
\hline
\end{tabular}


Task 1.4 (second level). Construct the concept table (Table 4) on the topic study "A quadratic residue modulo $m$ and a quadratic nonresidue modulo $m$ ".

This table should reflect new concepts, basic concepts, basic mathematical facts and the ways of proving them. In this table, terms for basic and new concepts should be provided in English. The wording of the basic mathematical facts and the ways of proving them should be represented in the native language.

Table 4. Conceptual Table for the Topic Study

\begin{tabular}{|c|c|c|c|}
\hline $\begin{array}{c}\text { New } \\
\text { concepts }\end{array}$ & $\begin{array}{c}\text { Basic } \\
\text { concepts }\end{array}$ & $\begin{array}{c}\text { Basic } \\
\text { mathematical } \\
\text { facts }\end{array}$ & $\begin{array}{c}\text { Methods and } \\
\text { techniques } \\
\text { used in proving }\end{array}$ \\
\hline & & & \\
\hline
\end{tabular}

Task 1.5 (second level). Create a cluster displaying a general scheme of ways to solve linear congruencies from the following concepts: "congruence with a variable", "linear congruence", "solution of the linear congruence", "module residues class", "modular multiplicative inverse of a congruence class", "congruence properties", "chain fractions", "equivalent congruencies", "co-prime integers".

Task 1.6 (third level). Read the given terms in Ukrainian (in English). Give analogues in English (in Ukrainian). Define the concepts in Ukrainian and in English. Complete Table 5.

Table 5. Define the Concepts in Ukrainian and in English

\begin{tabular}{|c|c|c|c|}
\hline $\begin{array}{c}\text { Term in } \\
\text { Ukrainian }\end{array}$ & $\begin{array}{c}\text { Term in } \\
\text { English }\end{array}$ & $\begin{array}{c}\text { Definition in } \\
\text { Ukrainian }\end{array}$ & $\begin{array}{c}\text { Definition in } \\
\text { English }\end{array}$ \\
\hline & & & \\
\hline
\end{tabular}

The second group of assignments consists of three-level tasks for bilingual operating with the wording of the mathematical statements. The first level tasks require establishing bilingual pairs of the wording of mathematical statements within a separate topic study. Level 2 tasks require filling in the blank spaces in bilingual wording of the mathematical statements. The third level tasks teach students to find and correct mistakes in bilingual wording of the mathematical statements. Here are some examples.

Task 2.1. (first level). Put the given Ukrainian statements in English and write down them in the form of congruencies (table 6).

Table 6. Statement in Ukrainian and in English

\begin{tabular}{|c|c|c|}
\hline $\begin{array}{c}\text { Statement in } \\
\text { Ukrainian }\end{array}$ & $\begin{array}{c}\text { Statement in } \\
\text { English }\end{array}$ & $\begin{array}{c}\text { Symbolic record of the } \\
\text { statement }\end{array}$ \\
\hline & & \\
\hline
\end{tabular}

Task 2.2. (first level). Give the wording of congruence properties in English and in Ukrainian (table 7).

Task 2.3. (second level). Fill in the blanks in the Ukrainian language statements. Formulate the statement in English. (An accompanying task is to fill in the gaps in the English language statements and formulate the statements in Ukrainian).

Note: the expected students' answers are given in italics in brackets.

1) If $\operatorname{GCD}(a, m)=d>1$ and the number $b$ is divisible by $d$, then the congruence $a x \equiv b(\bmod m)$ has (d solutions).

2) If $\operatorname{GCD}(a, m)=1$, then the congruence $a x \equiv b(\bmod m)$ has (the only solution).

3) If the $\operatorname{GCD}(a, m)=d>1$, and the number $b$ is not divisible by $d$, then the congruence $a x \equiv b(\bmod m)$ has (no solutions).

4) The congruence $22 x \equiv 9(\bmod 29)$ has the only solution because _ $(G C D(22,29)=1)$.

5) The congruence $192 x \equiv 9(\bmod 327)$ has three solutions because $(\operatorname{GCD}(192,327)=3$ and 9 is divided by 3 ).

6) The modular multiplicative inverse of an integer 17 modulo 67 is (4 modulo 67).

Table 7. Congruence Properties

\begin{tabular}{|l|c|c|}
\hline $\begin{array}{c}\text { The wording of the congruence } \\
\text { property in Ukrainian }\end{array}$ & $\begin{array}{c}\text { The wording of the congruence } \\
\text { property in English }\end{array}$ & \begin{tabular}{c} 
Symbolic record of the congruence property \\
\hline
\end{tabular} \\
\hline & $\begin{array}{c}\text { If } a \equiv b(\bmod m), \\
\text { then } a+c \equiv b+c(\bmod m)\end{array}$ \\
\hline & & $\begin{array}{c}\text { If } a \equiv b(\bmod m),(c, m)=1, \operatorname{then} a c \equiv b c(\bmod m) \\
\text { If } a \equiv b(\bmod m), \\
\text { then } a \equiv b+c m(\bmod m)\end{array}$ \\
\hline & $\begin{array}{r}\text { If } a \equiv b(\bmod m), m: d, \\
\text { then } a \equiv b(\bmod d)\end{array}$ \\
\hline
\end{tabular}


Task 2.4. (third level). Select the correct Ukrainian statements from the given ones. Find and correct the mistakes in the wrong statements. Put the correct statements in English.

Note: the expected students' answers are given in italics in brackets.

1) Numbers $a$ and $b$ are congruent modulo $m$ if they have the same reminders when divided by $m$ (correct).

2) 1 is the reminder of the division 78 by 11 , since $78=11 \cdot 7+1$ (correct).

3) The number 78 is congruent 27 modulo 11 (wrong).

4) The number 78 is not congruent 27 modulo 11, since 78 and 27 have different reminders of the division by11(correct).

5) $31 \equiv 9(\bmod 10)($ wrong $)$.

6) An arbitrary integer can be added to one part of the congruence (wrong); an arbitrary integer multiplied modulo can be added to one part of the congruence (correct).

7) Both parts of congruence can be divided by their common divisor (wrong); both parts of congruence can be divided by their common divisor co-prime modulo (correct).

8) $a \equiv b(\bmod m)$ in accordance to definition if $a=m p+$ $+r, b=m q+r, 0 \leq r \leq m ;($ wrong $) ; a \equiv b(\bmod m)$ in accordance to definition if $a=m p+r, b=m q+r$, $0 \leq r<m$ (correct).

9) If $a \equiv b(\bmod m)$, then $a k \equiv b k(\bmod m k)($ correct $)$.

An accompanying task is to choose the correct statements among English ones, to find and correct a mistake in the wrong statements, to give the wording of the correct statements in Ukrainian.

The next assignment may contain the following task: to find mistakes in the symbolic records of mathematical statements, to correct them, and to formulate correct statements in Ukrainian and English. Here is an example.

Task 2.5. (third level). Find mistakes in the symbolic records of the properties of congruence and correct them, give the wording of the properties of congruence in Ukrainian and in English:

Note: the expected students' answers are given in italics in brackets.

1) If $a \equiv b(\bmod m), b \equiv c(\bmod m)$, then $a \equiv b(\bmod n)$ (wrong).

2) If $a \equiv b(\bmod m), a \vdots c, b \vdots c$, then $(a / c \equiv b / c(\bmod m))$ (wrong).

3) If $a \equiv b(\bmod m), c \equiv d(\bmod m)$, then $a \pm c \equiv b \pm d$ $(\bmod m)$ and $a c \equiv b d(\bmod m)($ correct $)$.

4) If $a \equiv b(\bmod m)$, then $a^{n} \equiv b^{n}(\bmod m)($ correct $)$.

The third group includes the tasks for students to create bilingual related texts (comment to the solving of mathematical activities based on the concepts and their properties).
Task 3.1. Consider the proof of the multiplicativity of Euler's totient function [23, p. 82-83]. Make the following tasks (1-4) on the basis of the given theorem proof.

1) Reproduce the proof of the theorem in Ukrainian.

2) Give the bilingual answers to the questions on the basis of a given text.

3) Write down a short plan of the theorem proof in English.

4) Reproduce the theorem proof in English.

Task 3.2. Prove by congruence that the given equation $24^{x}+36^{y}=61^{z}$ has no natural solutions.

An expected students' reasoning:

«For the numbers on the left and right sides of the equation not to be equal, it is sufficient that they have different remainders of division by at least one number. Consider the remainders of division by 5 of the components on the left side of equation. $24^{x} \equiv(-1)^{x}(\bmod 5)$, $36^{y} \equiv 1(\bmod 5)$. Therefore, we may have two variants: 1$)$ $24^{x}+36^{y} \equiv 2(\bmod 5)$ at even values of $x$ or 2$) 24^{x}+36^{y} \equiv 0$ $(\bmod 5)$ at odd values of $x$. At the same time $61^{z} \equiv 1(\bmod 5)$ for any natural values of $z$. Therefore, the number expressions on the left and right sides of the equation have different remainders when divided by 5 , so the given equation doesn't have any natural solutions».

\section{Conclusions}

One of the significant results of secondary education is the formation of students' foreign language competence. This means that a teacher should also have such competence at a level not lower than students' one. The formation of a young professional's foreign language competence may be accomplished by extension or deepening of previously learnt mathematical content on the basis of the CLIL approach. The integrated foreign language and mathematical training of a future Mathematics teacher should be implemented within two stages, two consecutive models of ESP and CLIL.

The implementation of the CLIL model requires providing specific preconditions and thorough preparation. The preparatory steps of implementing CLIL for future Mathematics teachers include:

1) determining mathematical course as a basis for implementing the integrated learning of Mathematics and English;

2) choosing specific themes (units) of the course;

3) planning the expected results of the educational process;

4) designing the organizational features of the educational process using the CLIL method;

5) designing the appropriate teaching and methodological support of the integrated learning of Mathematics and English based on CLIL. 
The educational process should involve a special system of multilevel bilingual assignments.

In our further research, we plan to identify positive aspects of the CLIL approach and risks in its implementation in terms of forming and developing subject mathematical and foreign language communicative (linguistic) competence of future Mathematics teachers.

\section{REFERENCES}

[1] CLIL: An interview with Professor David Marsh (2008). Retrieved from http://ihjournal.com/content-and-language-integrated-learning

[2] Wielander, E. (2013). Something to talk about: Integrating content and language study in higher education. Retrieved from https://www.unifg.it/sites/default/files/llegatiparagraf o//22-01-2014/wielander_what_is_clil-clil_at_aston_ _university.pdf

[3] Hanesová, D. (2015). History of CLIL. In Pokrivčáková, S. et al. (2015). CLIL in Foreign Language Education: e-textbook for foreign language teachers. Nitra: Constantine the Philosopher University. Retrieved from: https://www.unifg.it/sites/default/files/allegatiparagrafo/06 -07-2017/hanesova_history_of_clil.pdf

[4] Marsh, D. (1994). Bilingual education \& content and language integrated learning. International Association for Cross-Cultural Communication, Language Teaching in the Member States of the European Union (Lingua), Paris: University of Sorbonne.

[5] Cambridge Dictionary. Cambridge University Press. Retrieved from: https://www.cambridgeenglish.org/Images / /22194-tkt-clil-glossary-document.pdf

[6] European Council. (2005). Content and Language Integrated Learning (CLIL) at School in Europe. Retrieved from http://www.indire.it/lucabas/lkmw_file/eurydice/ /CLIL_EN.pdf

[7] Dudley-Evans, T., St John, Maggie Jo. (2011). Developments in English for Specific Purposes (A multi-disciplinary approach). Cambridge: Cambridge University Press.

[8] Inozemtseva, K. M., Bondaletova, E. N., Borisova, T. D. (2016). Evolution of ESP as a methodology of teaching a foreign language for professional use in non-linguistic universities in Russia. Gumanitarnye nauchnye issledovaniya, 2. Retrieved fromhttp://human.snauka.ru/20 $16 / 02 / 13994$

[9] Inozemtseva, K. M. (2014) ESP teachers' professional development in the internationalization context. European conference on education and applied psychology. Vienna, 14 May.

[10] Ioannou Georgiou, S., Pavlu, P. (2015). Guidelines for CLIL Implementation in Primary and Preprimary Education. Comenius Socrates Project.

[11] Bystray, Y., Belova, L., Vlasenko, O., Zasedateleva, M.,
Shtykova, T. (2018). Development of second-language communicative competence of prospective teachers based on the CLIL Technology (From the experience of a pedagogic project at a Department of History). Revista Espacios, 39 (52), 12. Retrieved from http://www.revistaes pacios.com//a18v39n52/18395212.html

[12] Marsh, D. (2002). Content and Language Integrated Learning: The European Dimension Actions, Trends and Foresight Potential. DG Education \& Culture, European Commission.

[13] Coyle, D., Hood, P., \& Marsh, M. (2010). Content and Language Integrated Learning. Cambridge: Cambridge University Press.

[14] Coyle, D. (1999) Supporting students in CLIL contexts: planning for effective classrooms. In Masih, J. (1999). Learning through a foreign language: models, methods and outcomes, London, CILT.

[15] Surmont, J., Struys, E., Van Den Noort, M., Van De Craen, P. (2016). The effects of CLIL on mathematical content learning: A longitudinal study. Studies in Second Language Learning and Teaching, 6 (2), 319-337. Retrieved from https://doi.org/10.14746/ssllt.2016.6.2.7

[16] Mehisto, P., Marsh, D., \& Frigols Martin, M. Je. (2008). Uncovering CLIL: Content and Language Integrated Learning in Bilingual and Multilingual Education. Oxford: Macmillan.

[17] Dalton-Puffer, C. (2006). Discourse in Content and Language Integrated Learning (CLIL) Classrooms. Amsterdam: John Benjamins.

[18] Käbin, E. (2016). Content and Language Integrated Learning (CLIL). Language: EN. Retrieved from : https: //epale.ec.europa.eu/en/blog/content-and-language-integrat ed-learning-clil

[19] Lorenzo, F., Trujillo, F. \& Vez, M. (2011). Educación bilingüe. Integración de contenidos y segundas lenguas. Madrid: Síntesis.

[20] Vlasenko, K., Lovyanova, I., Chumak, O., Sitak, I., \& Kalashnykova, T. (2019). The formation of foreign language competence of engineering students through CLILmethod. Revista Dilemas Contemporáneos: Educación, Política y Valores. Year VII, Special Edition, November 2019. Retrieved from https://dilemascontempor aneoseducacionpoliticayvalores.com/_files/200006243-e84 c1e84c3/EE\%2019.11.68\%20La\%20formaci\%C3\%B3n\% $20 \mathrm{del} \% 20$ conocimiento $\% 20 \mathrm{de} \% 20$ lenguas $\% 20$ extranjeras $\% 20 \mathrm{de}$.....pdf

[21] Surmont, J., Struys, E., Van Den Noort, M., \& Van De Craen, P. (2016). The Effects of CLIL on Mathematical Content Learning: A Longitudinal Study Studies in Second Language Learning and Teaching, 6 (2), 319-337. Retrieved from https://doi.org/10.14746/ssllt.2016.6.2.7

[22] Teaching Mathematics through English - Teaching English through Mathematics. Comenius Project "Two Highways of Life - Maths and English". Retrieved from https://clilmaths.jimdo.com

[23] Akulenko, I., Leshchenko, Yu., \& Vasilenko, I. (2018). Teaching Proofs of Mathematical Statements in the In-Depth Learning of Mathematics. Current Status and Prospects of Mathematical Education: [monograph]. Eds. 
prof. N. Tarasenkova, \& L. Kyba. Budapest: SCASPEE, 75-89.

[24] Akulenko, I., Leshchenko, Yu., Krasnoshlyk, N. (2016). Elements of cryptology. Materials for Interdisciplinary (Mathematics and Informatics) Elective Course for Secondary School Students. Cherkasy. [In Ukr.]

[25] Akulenko, I., Leshchenko, Yu., Krasnoshlyk, N. (2015). Interdisciplinary Elective Courses in the Educational Process in The Basic School. Society for Cultural and Scientific Progress in Central and Eastern Europe: Urgent problems of Pedagogy and Psychology. Budapest, 2015, July 19th. Retrieved from: http://scaspee.com/6/post/2015/ 07//interdisciplinary-elective-courses-in-secondary-schooltraining-akulenkoia-krasnoshlykno-leshchenkoyuyu.html. [In Ukr.]

[26] Tarasenkova, N. (2013). The quality of mathematical education in the context of Semiotics. American Journal of Educational Research. 2013. 1, no. 11: 464-471. Doi: 10.12691/education-1-11-2.

[27] Tarasenkova, N. (2014). Peculiar Features of Verbal Formulations in School Mathematics. Global Journal of Human-Social science : G : Linguistics \& Education, 14 (3). 61-67.

[28] Tarasenkova, N., Borkach, E. (2016). The system of bilingual tasks for students of natural and mathematical specialties of universities with Hungarian language of instruction. Science and education a new dimension, IV (40), Issue: 81. 66-69. [In Ukr.].

[29] Favilli, F., Maffei, L., Peroni R. (2013) Teaching and Learning Mathematics in a Non-native Language: Introduction of the CLIL Methodology in Italy University of Pisa, Pisa, Italy US-China Education Review, June 2013, Vol. 3, No. 6, 374-380.

[30] Miqdadi, R., \& Al-Jamal, D. (2013) Difficulties in Content and Language Integrated Learning: The Case of Math. Jordan Journal of Educational Sciences Vol. 9, No. 4, 2013, pp 449-459.

[31] Safarova, A. M. (2016). Learning a foreign language using elements of the modern CLIL methodology in the educational process. Pedagogical skill: materials of the VIII Intern. scientific conf., Moscow, June 2016, Buki-Vedi, 14- 17. Retrieved from https://moluch.ru/conf/ped/archive/ 191/10645/ [In Rus.] 